\title{
Dynamics of the water surface of the Eravno-Khorginsky system (Western Transbaikalia) in 1990-2020 according to remote sensing data
}

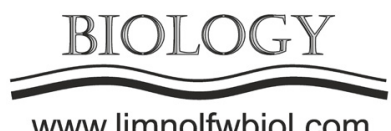

www.limnolfwbiol.com

\author{
Zamana L.V. ${ }^{1}$, Vakhnina I.L. ${ }^{1,2}$, Golyatina M.A. ${ }^{3}$, Noskova E.V. ${ }^{1}$ \\ ${ }^{1}$ Institute of Natural Resources, Ecology and Cryology, Siberian Branch of the Russian Academy of Sciences, Nedorezova Str., 16a, \\ Chita, 672014, Russia \\ ${ }^{2}$ Siberian Federal University, Svobodny Av., 79, Krasnoyarsk, 660041, Russia \\ ${ }^{3}$ State Research Center "Planeta", Bolshoy Predtechensky Str. 7, Moscow, 123242, Russia
}

\begin{abstract}
According to space sounding data using the MNDWI index, the dynamics of changes in the water surface of 17 lakes in the Eravno-Khorginsky system over the past 30 years has been determined. The greatest drying up of the lakes occurs in 2020, some lakes have completely dried up. The water surface of Lake Mal. Eravnoe, the second largest in the system, decreased from $62.57 \mathrm{~km}^{2}$ in 1991 to $5.26 \mathrm{~km}^{2}$ in 2020. Currently, all the lakes are closed, previously the largest, excluding the lake Gunda, at high levels they were connected by a channel and had a runoff in the river Vitim. Nevertheless, the areas of water areas of the lakes varied consistently, the correlation coefficients between all lakes varied in the range of 0.46-0.99. To clarify the main factors affecting the drying of lakes, in addition to the data on atmospheric precipitation and air temperature, the calculated hydrothermal moisture coefficient G.T. Selyaninov and aridity index D.A. Pedya. Correlation analysis showed that the increase in air temperature over the past three decades has a more major impact on the reduction of the lake water area.
\end{abstract}

Keywords: lakes, water surface, remote sensing, drying up, climate influence

The lakes of the Eravno-Khorginsky system, located in the south-west of the Vitim plateau in the watershed of the Uda River (Lake Baikal basin) and Vitim River (Lena river basin), have more than 200 water bodies (Plusnin and Peryazeva, 2012). Most of them belong to the category of small lakes, the area only of Lake Bol. Eravnoe slightly exceeds $100 \mathrm{~km}^{2}$. At present, all of them, and earlier in the period of high levels, with the exception of a few, connected by the Kholoy stream flowing into the Vitim, are without outlet. Until recently, commercial fishing was carried out on the lakes, which is practically lost due to their drying up, which has sharply increased in recent years.

Analysis of the water dynamics of lakes in the form of changes in their water areas was carried out according to remote sensing data. To identify the water surface of lakes (WS) remotely, we used data from Landsat spacecraft with a spatial resolution of $30 \mathrm{~m}$. For the summer low-water period of each year, the best image with the least cloud cover (less than 10\%) was selected. The WS areas were obtained as a result of the application of an automated method for decoding satellite images by the spectral index MNDWI (Xu, 2006) due to its highest accuracy in comparison with other indices (Kurganovich and Noskova, 2015). To calculate the MNDWI, a combination of visible Green $(0.525-0.600 \mu \mathrm{m})$ and near shortwave infrared SWIR $(1.560-1.660 \mu \mathrm{m})$ spectra is used:

$$
M N D W I=\frac{(\text { Gresn }-S W I R)}{(\text { Gresn }+S W I R)}
$$

Access to satellite data and calculations of the areas of the water surface of lakes was carried out in the VEGA-Science service (http://sci-vega.ru/), which is part of the IKI-Monitoring Centre Collective Use (Loupian et al., 2019).

The extreme values of WS of the most lakes for the period under consideration are presented in the Table. The dynamics of the WS change for the nondrying first six lakes indicated in the Table is shown in the figure. All lakes are characterized by a negative trend of changes in the water areas with the coefficients $\mathrm{R}^{2}$ values 0.5834-0.9335, while in the last twenty years its slope, except for Lake Isinga, has increased. This testifies to a more intensive reduction in the lake water areas during this period. Many lakes, as can be seen from the Table, completely dried up during these years. Other lakes have the same tendency, which is confirmed by the pair correlation coefficients, the values of which

*Corresponding author.

E-mail address: vahnina_il@mail.ru (I.L. Vakhnina) 
Table. Maximum and minimum areas of the Eravno-Khorginsky system lakes in 1990-2020

\begin{tabular}{|c|c|c|c|c|}
\hline Lake & Maximum, $\mathrm{km}^{2}$ & Year & Minimum, $\mathrm{km}^{2}$ & Year \\
\hline Bol'shoe Eravnoe & 105.855 & 1991 & 93.444 & 2020 \\
\hline Maloe Eravnoe & 62.573 & 1991 & 5.260 & 2020 \\
\hline Isinga & 34.800 & 1991 & 30.965 & 2017 \\
\hline Khorga & 31.263 & 1991 & 18.872 & 2020 \\
\hline Sosnovoe & 25.531 & 1991 & 14.746 & 2020 \\
\hline Gunda & 13.381 & 1992 & 10.616 & 2020 \\
\hline Khaymisanovskoe & 8.37212 & 1992 & 0 & $2013-2020$ \\
\hline Malaya Khorga & 7.229 & 2010 & 3.180 & 2020 \\
\hline Ukyr & 4.143 & 1993 & 0 & 2006-2007, 2009, 2015, 2020 \\
\hline Khogotuy & 3.051 & 1991 & 0.011 & 2017 \\
\hline Dolgoe & 2.468 & 1993 & 1.363 & 2020 \\
\hline Eksend & 1.691 & 1992 & 0 & $2011-2020$ \\
\hline Arshan & 1.422 & 1993 & 0.788 & 2020 \\
\hline Burgunda & 1.264171 & 1990 & 0 & 2007, 2009, 2015 \\
\hline Khorkhoyta & 1.05301 & 1991 & 0 & 2017 \\
\hline Shinista & 1.04395 & 1991 & 0.089 & 2020 \\
\hline
\end{tabular}

are in the range of $0.46-0.99$.

To elucidate the influence of climatic conditions on the dynamics of changes in the water areas of the lakes, we used the data of the Zabaikalsky UGMS on atmospheric precipitation and air temperature from the Sosnovo-Ozerskoye meteorological station $\left(52^{\circ} 32^{\prime} \mathrm{N}\right.$, $111^{\circ} 33^{\prime} \mathrm{E}, 952 \mathrm{~m}$ above sea level), located on the shore of Lake Sosnovoe, as well as the hydrothermal moisture coefficient (HMC) of Selyaninov and the Pedya aridity index calculated from these data, the calculation formulas for which are given in (Cherenkova, 2013).

The average annual air temperature in the area of the meteorological station is negative, for 70 years (1950-2019), on average, it is $-3.2^{\circ}$ C. The lowest average air temperature is in January $\left(-24.0^{\circ} \mathrm{C}\right)$, the highest - in July $\left(+16.6^{\circ} \mathrm{C}\right)$. Analysis of the deviation of air temperature values from the average for the base period 1981-2010 showed a significant increase in the average annual $t$ in the last 30 years. Atmospheric precipitation in the study area falls on average about $310 \mathrm{~mm}$ per year. The maximum precipitation is observed in summer (66\% of the annual amount), while July-August accounts for an average of $51 \%$ of the annual precipitation. In the long-term course, the unidirectional trend is not traced due to the alternation of years with increased or decreased their amount.

As the analysis has shown, the air temperature has a more significant effect on the decrease in the water areas of the lakes than atmospheric precipitation. In some cases, the areas of lakes have a positive

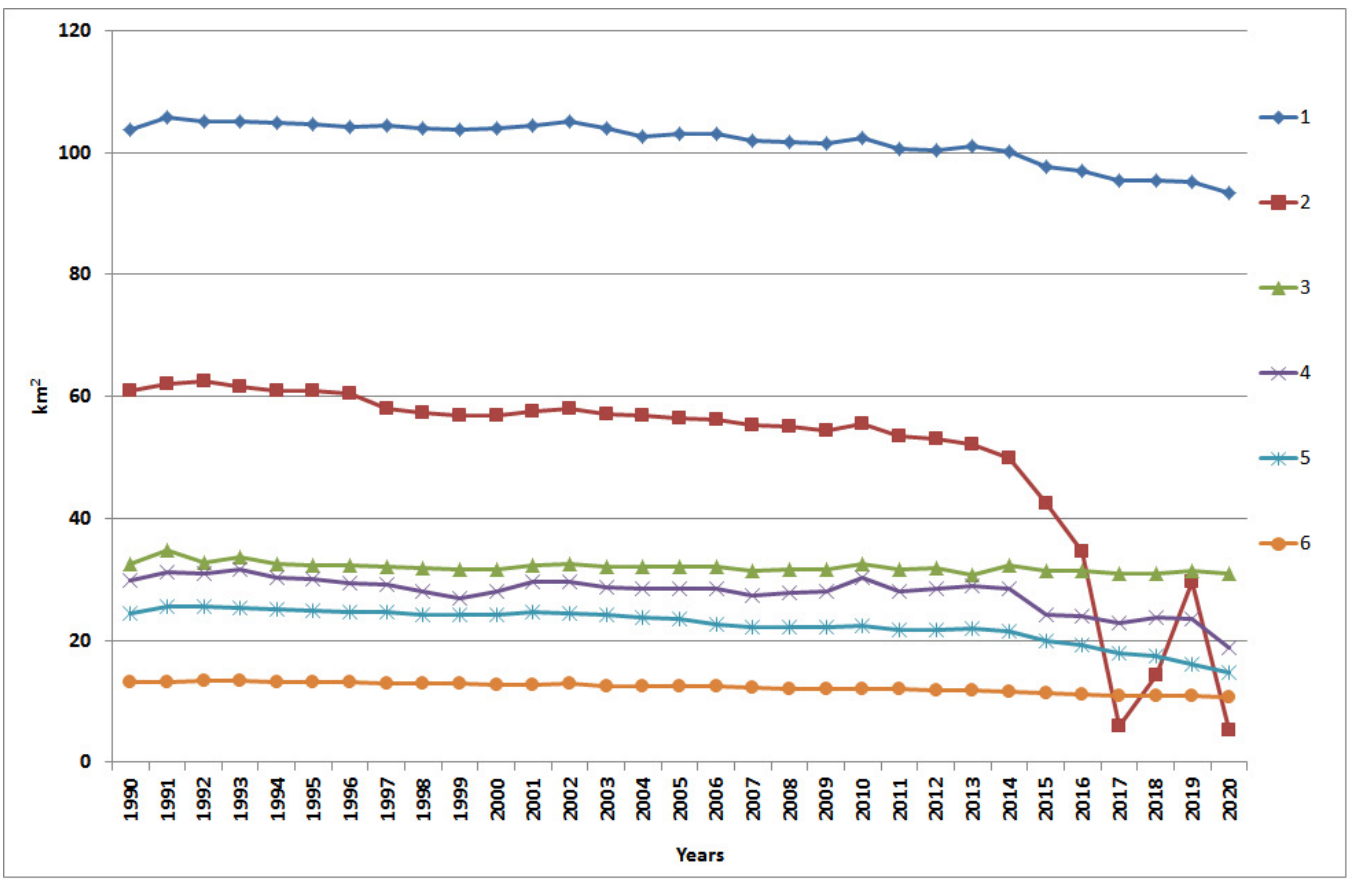

Fig. Dynamics of changes in the WS of the largest lakes of the Eravno-Khorginsky system: 1 - Bol. Eravnoe, 2 - Mal. Eravnoe, 3 - Isinga, 4 - Khorga, 5 - Sosnovoe. 6 - Gunda. 
correlation only with precipitation in April and August $(\mathrm{r}=0.28-0.44)$. A negative correlation between air temperature and water area $(r=-0.27 \ldots-0.47)$ for one or several months from March to September was noted for all lakes, which is caused by a more significant role of evaporation in comparison with precipitation. The same correlation $(r=-0.26 \ldots-0.45)$ with the Pedya index, calculated from the difference in the ratios of air temperature and precipitation anomalies to their standard deviations, also indicates the main role of air temperature in the decrease of WS. The same is confirmed by the HMC, which, on the contrary, has positive values of $r(0.26 \ldots 0.38)$, since it is determined by the ratio of precipitation / air temperature.

\section{Acknowledgments}

The analysis of climatic conditions and the results obtained was carried out according to the budget research projects of the INREC SB RAS, the interpretation of space images was carried out with the financial support of the Russian Science Foundation (project No. 19-14-00028).

\section{References}

Cherenkova A.E. 2013. Quantitative estimates of atmospheric drought in the federal districts of the European territory of Russia. Izvestiya Rossiyskoy Akademii Nauk. Seriya Geograficheskaya [Regional Research of Russia] 6: 76-85. (in Russian)

Kurganovich A.K., Noskova E.A. 2015. The estimation of water surface variations of steppe soda lakes in the southeast of Transbaikalie with using of remote sensing of water indices. Vestnik Zabaykal'skogo Gosudarstvennogo Universiteta [Transbaikal State University Bulletin] 6(121): 16-24. (in Russian)

Loupian E.A., Proshin A.A., Bourtsev M.A. et al. 2019. Experience of development and operation of the IKI-Monitoring center for collective use of systems for archiving, processing and analyzing satellite data. Sovremennye Problemy Distantsionnogo Zondirovaniya Zemli iz Kosmosa [Modern Problems of Remote Sensing of the Earth from Space] 16(3): 151-170. (in Russian)

Plusnin A.M., Peryazeva E.G. 2012. Hydrological and hydrochemical characteristics of the lakes in the Eravninskaya depression. Geography and Natural Resources 33(2): 136-141. DOI: $10.1134 /$ S1875372812020060

$\mathrm{Xu} \mathrm{H.} \mathrm{2006.} \mathrm{Modification} \mathrm{of} \mathrm{normalized} \mathrm{difference} \mathrm{water}$ index (NDWI) to enhance open water features in remotely sensed imagery. International Journal of Remote Sensing 27: 3025-3033. DOI: 10.1080/01431160600589179 